\title{
Produção de resíduos sólidos domésticos e a preocupação com o meio ambiente no estado do Pará
}

Production of domestic solid waste and the concern with the environment in the state of Pará

Producción de residuos sólidos domésticos y preocupación por el medio ambiente en el estado de Pará

Argel da Silva Modesto ORCID: https://orcid.org/0000-0002-2828-2228 Universidade Federal Rural da Amazônia, Brasil E-mail: argelmodesto.53@gmail.com

Camila da Silva Aroucha ORCID: https://orcid.org/0000-0001-6746-8423 Universidade Federal Rural da Amazônia, Brasil

E-mail: camila31.39@gmail.com

Elivelton Rafael Silva dos Santos ORCID: https://orcid.org/0000-0001-9581-8304 Universidade Federal Rural da Amazônia, Brasil

E-mail: rafael.headbangermetal@gmail.com

Emilly Santiago Magalhães

ORCID: https://orcid.org/0000-0002-0428-3592 Universidade Federal Rural da Amazônia, Brasil E-mail: emillysantiago100@gmail.com

João Victor Pinheiro Costa ORCID: https://orcid.org/0000-0001-8376-0838 Universidade Federal Rural da Amazônia, Brasil E-mail: joaovicpcosta@gmail.com

Kessely Vieira de Oliveira ORCID: https://orcid.org/0000-0002-4637-1021 Universidade Federal Rural da Amazônia, Brasil E-mail: kessilyvieira123@gmail.com

Maria Alessandra Coelho da Silva ORCID: https://orcid.org/0000-0001-2345-6789 Universidade Federal Rural da Amazônia, Brasil E-mail: alessandra04dasilv@gmail.com

Maria Iara Pinto da Cruz ORCID: https://orcid.org/0000-0002-3180-0911 Universidade Federal Rural da Amazônia, Brasil E-mail: iaracruz057@gmail.com

Taina Silva Queiroz

ORCID: https://orcid.org/0000-0001-7622-9379 Universidade Federal Rural da Amazônia, Brasil E-mail: tainaqueiroz147@gmail.com

Zara Carolyne da Silva Gonçalves ORCID: https://orcid.org/0000-0002-3229-669X Universidade Federal Rural da Amazônia, Brasil E-mail: zaracarolyne5@gmail.com

Maria Júlia Silva dos Santos ORCID: https://orcid.org/0000-0003-4207-1715 Universidade Federal Rural da Amazônia, Brasil E-mail: juliasantos414@gmail.com

Sara Souza de Jesus de Oliveira ORCID: https://orcid.org/ 0000-0003-1879-9335 Universidade Federal Rural da Amazônia, Brasil E-mail: sara.jesus0303@gmail.com 


\author{
Alessandra Epifanio Rodrigues \\ ORCID: https://orcid.org/0000-0002-8375-2923 \\ Universidade Federal Rural da Amazônia, Brasil \\ E-mail: alessandra.epifanio@ufra.edu.br \\ Bárbara Rodrigues de Quadros \\ ORCID: https://orcid.org/0000-0001-7052-4326 \\ Universidade Federal Rural da Amazônia, Brasil \\ E-mail: barbara.quadros@ufra.edu.br \\ Vanessa Mayara Souza Pamplona \\ ORCID: https://orcid.org/0000-0002-2461-2103 \\ Universidade Federal Rural da Amazônia, Brasil \\ E-mail: vanessa.pamplona@ufra.edu.br
}

\title{
Resumo
}

O trabalho buscou compreender a percepção da população paraense a respeito do lixo que produzem e como lidam com ele, objetivando compreender os efeitos que o mesmo causa no meio socioambiental; no qual, a maioria das vezes é uma problemática para a maior parte das cidades brasileiras. Para tanto, foram analisados dados anônimos por meio de uma pesquisa de campo virtual, onde foi utilizado o método quantitativo descritivo. Os dados da pesquisa foram coletados através da plataforma Google Forms, 435 pessoas responderam ao questionário que continha 21 perguntas, divididas em duas categorias: a identificação pessoal do entrevistado, e o conhecimento da população a respeito do consumo e produção de lixo. Posteriormente, foram analisados todos os dados estatísticos por meio de gráficos e tabelas, e dentre os principais resultados da pesquisa notou-se que entre a maioria dos entrevistados há uma preocupação com as questões ambientais, porém uma parte dos que foram questionados não possuem consciência do que acontece com os resíduos produzidos por eles. Diante disso, há uma necessidade em fortalecer mais quanto a políticas sobre a coleta seletiva de lixo.

Palavras-chave: Meio ambiente; Coleta seletiva; Reciclagem; Sustentabilidade.

\section{Abstract}

The work sought to understand the perception of the Pará population about the waste they produce and how they deal with it, aiming to understand the effects it causes in the socio-environmental environment; which, most of the times, is a problem for most Brazilian cities. For this purpose, anonymous data were analyzed through a virtual field research, where the descriptive quantitative method was used. The survey data were collected through the Google Forms platform, 435 people answered the questionnaire that contained 21 questions, divided into two categories: the personal identification of the respondent, and the population's knowledge about the consumption and production of waste. Subsequently, all statistical data were analyzed using graphs and tables, and among the main results of the survey it was noted that among the majority of respondents there is a concern with environmental issues, but a part of those questioned are not aware of the what happens with the waste produced by them. Given this, there is a need to strengthen more policies on selective waste collection.
\end{abstract}

Keywords: Environment; Selective collection; Recycling; Sustainability.

\section{Resumen}

El trabajo buscó conocer la percepción de la población de Pará sobre los residuos que producen y cómo los tratan, con el objetivo de entender los efectos que causan en el entorno socio-ambiental; lo que, la mayoría de las veces, es un problema para la mayoría de las ciudades brasileñas. Para ello, se analizaron datos anónimos a través de una investigación de campo virtual, donde se utilizó el método cuantitativo descriptivo. Los datos de la encuesta fueron recogidos a través de la plataforma Google Forms, 435 personas respondieron al cuestionario que contenía 21 preguntas, divididas en dos categorías: la identificación personal del encuestado, y el conocimiento de la población sobre el consumo y la producción de residuos. Posteriormente, se analizaron todos los datos estadísticos mediante gráficos y tablas, y entre los principales resultados de la encuesta se observó que entre la mayoría de los encuestados existe una preocupación por las cuestiones medioambientales, pero una parte de los encuestados no es consciente de lo que ocurre con los residuos que produce. Por ello, es necesario reforzar las políticas de recogida selectiva de residuos.

Palabras clave: Medio ambiente; Recogida selectiva; Reciclaje; Sostenibilidad.

\section{Introdução}

Em 2021, no cenário mundial ocorre um crescimento em massa da população em centros urbanos, à medida que ocorre esse aumento, também cresce a geração de resíduos sólidos por consequência de atividades humanas. Silva (2004) destaca que a grande quantidade de lixo produzido diariamente no mundo, transforma-se em prejuízos ambientais e passa a 
agravar a qualidade de vida das pessoas, por isso que temas como o impacto ambiental e a sustentabilidade estão sendo pautas importantíssimas no mundo inteiro, justamente pelo aumento excessivo de pessoas na zona urbana, que além da produção em massa de lixo, não sabem como fazer o descarte adequado.

Dados da Pesquisa Nacional por Amostra de Domicílios (IBGE, 2015), mostram que o Brasil teve mais de 173 milhões de habitantes residentes em área urbana (84,72\% da população) e que chegaram a produzir 79,9 milhões de toneladas de lixo. Esse resultado posicionou o Brasil como o $4^{\circ}$ maior gerador de resíduos sólidos no mundo. De acordo com o censo do Instituto Brasileiro de Geografia e Estatísticas (IBGE, 2019), a população brasileira foi estimada em mais de 211 milhões de habitantes, onde houve uma produção de 79,1 milhões de toneladas de lixos, 40\% destes, sendo descartados incorretamente. Este cenário nacional revela o quanto alguns estados ainda precisam avançar no que diz respeito a medir esforços para a melhor gestão do lixo.

Os resíduos sólidos, na maioria das vezes constituem uma problemática para a maior parte das cidades brasileiras. Mucelin (2008) afirma que isso se deve ao fato de que muitos municípios ainda não contam com infraestrutura e serviços públicos adequados que abrangem o descarte correto desses resíduos. Quase metade dos 5.570 municípios brasileiros (49,9\%) ainda despeja seus resíduos sólidos em lixões ou em depósitos irregulares e ilegais de lixo (Agência Brasil, 2020). No ano de 2020, apenas 41,5\% das prefeituras do país adotaram algum tipo de sistema para o manejo destes resíduos, e infelizmente nem todas essas iniciativas obtiveram sucesso e/ou progresso (Gandra, 2020).

A maneira como os resíduos sólidos são descartados é uma das questões ambientais mais desafiadoras para o desenvolvimento do país, principalmente em áreas urbanas. Vassanadunrongdee \& Kittipongvises (2018) observaram que o destino e o tratamento de resíduos sólidos são temas relevantes a serem discutidos, isto é, representam um problema socioambiental grave de nossa era e que processa ser enfrentado.

No Brasil, há leis que protegem o meio ambiente e a saúde pública, com penas e infração, caso não haja o cumprimento dela. É o caso da Lei n ${ }^{\circ}$ 12.305/10 (Brasil, 2010) que institui a Política Nacional de Resíduos Sólidos; lei federal, válida em todo o território nacional, criada com o intuito de reduzir o impacto de resíduos sólidos no meio ambiente, contendo diretrizes que influenciam para o bom funcionamento da saúde pública, definindo um conjunto de ações voltadas para buscar soluções de forma que abrange áreas públicas, econômicas, ambientais, culturais e sociais sob a ideia inicial de desenvolvimento sustentável.

Segundo Farias (2019), a população exerce um papel importante, pois são responsáveis pela destinação correta pósconsumo de seus resíduos, e atuam como agentes fiscalizadores das ações e gerenciamentos do mesmo, e infelizmente estas leis ainda não tem um grande alcance em pequenas cidades, zonas rurais e até mesmo estados que não são desenvolvidos, como é o caso do Pará; considerado pela Associação de Empresas e Limpeza Pública e Resíduos Especiais (Abrelpe, 2017) o estado que menos aproveita o lixo para a reciclagem, estando entre os piores índices de coleta de resíduos sólidos, isto é, pouco mais de 76\% do lixo produzido é coletado, e apenas 0,48\% desses resíduos chegam a ser reciclados (G1 PA, 2021). É importante destacar que em muitas cidades no Pará, o descarte de lixo ainda é inadequado, onde o caminhão de lixo não faz a coleta.

As campanhas realizadas pelos governos e prefeituras de conscientização da população sobre a coleta seletiva e reciclagem têm como objetivo a redução de futuros impactos ambientais. Cornieri (2010) afirma que neste contexto, a reciclagem é considerada uma alternativa de solução para a diminuição de lixo produzido, com um sistema que traz benefícios como: prevenção à poluição do solo, da água e atmosférica; economia de água e energia, geração de trabalho e renda para catadores, além de prolongar a vida útil de aterros sanitários. Em várias cidades, a reciclagem mostra resultados positivos, além de auxiliar na mudança de postura social em relação ao lixo. Vilhena (1999) menciona que a coleta seletiva, também é uma alternativa cotada para a diminuição de problemas ambientais, pois este sistema de seleção recolhe materiais recicláveis 
como papéis, plásticos, vidros e metais, separando-os previamente para uma etapa de triagem de pré-beneficiamento que será vendido a empresas reguladoras.

Há poucas pesquisas sobre a opinião da população referente à produção de lixo no estado e de como os resíduos sólidos causam impactos não apenas ao meio ambiente, mas também no dia a dia da população. Diante desse cenário, objetivase avaliar a percepção da população sobre os efeitos socioambientais causados pela produção de lixo.

\section{Metodologia}

O estudo foi realizado no estado do Pará, localizado na região norte do Brasil, com área equivalente a $1.245 .870 \mathrm{~km}^{2}$, e um total de 8.690.745 habitantes, de acordo com Instituto Brasileiro de Geografia e Estatística (IBGE, 2020), sendo considerado o estado nortista brasileiro mais populoso. É dividido em 144 municípios e seis mesorregiões.

A pesquisa teve caráter de estudo quali-quantitativo (Pereira, et al., 2018), em que os dados do estudo foram coletados por meio da aplicação de um questionário virtual por meio do aplicativo Google Forms, estruturado com perguntas objetivas e em linguagem acessível, com possibilidade de mais de uma resposta em algumas perguntas. As variáveis estudadas estão apresentadas no Quadro 1. O link para responder o questionário foi divulgado nas redes sociais, no período de 06 de julho a 15 de julho de 2021.

Quadro 1 - Descrição das variáveis utilizadas no questionário.

\begin{tabular}{|c|c|}
\hline Características & Variáveis \\
\hline \multirow{5}{*}{ Identificação do entrevistado (a) } & Gênero \\
\hline & Faixa etária \\
\hline & Cidade de residência \\
\hline & Zona de residência \\
\hline & Nível de escolaridade \\
\hline \multirow{8}{*}{$\begin{array}{l}\text { A produção de lixo e a preocupação com o } \\
\text { meio ambiente }\end{array}$} & Preocupação com as questões ambientais \\
\hline & Consciência ambiental \\
\hline & Descarte incorreto do lixo \\
\hline & Preocupação com produtos que agridem o meio ambiente \\
\hline & Quantidade de lixeiras disponíveis na rua \\
\hline & Coleta de lixo pela gestão da prefeitura \\
\hline & Coleta seletiva \\
\hline & Reciclagem \\
\hline
\end{tabular}

Fonte: Autores.

Para a coleta de dados foi utilizada a técnica de amostragem não probabilística por conveniência, totalizando 435 respostas. O questionário abordava perguntas sobre as características socioeconômicas e sobre a produção de lixo e os seus impactos ao meio ambiente.

Os dados coletados foram exportados para uma planilha do Microsoft Excel, e posteriormente foi realizada a análise estatística com o objetivo de organizar os resultados em gráficos e tabelas, para estabelecer uma melhor compreensão das informações obtidas.

\section{Resultados e Discussão}

A maioria dos entrevistados está na faixa etária entre 18 e 25 anos (78,4\%), sendo moradores de três principais 
cidades, localizadas na mesorregião nordeste do estado e com número inferior a 120.000 habitantes: (Paragominas (40,7\%), Aurora do Pará (17,0\%) e Tailândia (13,3\%)), sendo 85,7\% dos participantes residentes de zona urbana. Em relação ao grau de escolaridade, $35,9 \%$ possuem curso superior incompleto e $28,7 \%$ ensino médio completo, logo, a maior parte possui um bom nível de instrução (Tabela 1).

Tabela 1 - Percentual dos entrevistados no estado do Pará, ano 2021, por faixa etária, cidades, zonas e grau de escolaridade.

\begin{tabular}{|c|c|}
\hline Variável & $\%$ \\
\hline \multicolumn{2}{|l|}{ Faixa Etária } \\
\hline De 18 e 25 anos & 78,39 \\
\hline De 26 e 33 anos & 11,95 \\
\hline De 34 e 40 anos & 5,52 \\
\hline De 41 e 48 anos & 2,99 \\
\hline De 49 e 56 anos & 0,46 \\
\hline De 57 a 65 anos & 0,69 \\
\hline \multicolumn{2}{|l|}{ Cidades } \\
\hline Paragominas & 40,69 \\
\hline Aurora do Pará & 17,01 \\
\hline Tailândia & 13,33 \\
\hline Belém & 7,59 \\
\hline Castanhal & 3,22 \\
\hline Acará & 2,76 \\
\hline Mãe do Rio & 2,30 \\
\hline Moju & 1,60 \\
\hline Ipixuna do Pará & 1,38 \\
\hline Curralinho & 1,38 \\
\hline Parauapebas & 1,15 \\
\hline Bagre & 0,92 \\
\hline Barcarena & 0,69 \\
\hline Tomé-Açu & 0,46 \\
\hline São Miguel do Guamá & 0,46 \\
\hline São Domingos do Capim & 0,46 \\
\hline Dom Eliseu & 0,46 \\
\hline Ananindeua & 0,46 \\
\hline Outras & 3,68 \\
\hline \multicolumn{2}{|l|}{ Zonas } \\
\hline Zona Urbana & 85,75 \\
\hline Zona Rural & 14,25 \\
\hline \multicolumn{2}{|l|}{ Grau de Escolaridade } \\
\hline Ensino fundamental incompleto & 2,76 \\
\hline Ensino fundamental completo & 2,07 \\
\hline Ensino médio incompleto & 9,20 \\
\hline Ensino médio completo & 28,74 \\
\hline Curso técnico incompleto & 3,22 \\
\hline Curso técnico completo & 7,36 \\
\hline Curso superior incompleto & 35,86 \\
\hline Curso superior completo & 6,44 \\
\hline Curso pós-graduação incompleto & 0,92 \\
\hline Curso pós-graduação completo & 3,45 \\
\hline
\end{tabular}

Fonte: Autores (2021). 
Com a aplicação do questionário foi possível identificar sobre o conhecimento da população e sua preocupação com a produção de lixo e preservação do meio ambiente, onde $99,1 \%$ afirmaram se preocupar com as questões ambientais, porém apenas $25,5 \%$ consideraram que os moradores de suas regiões também possuem essa preocupação, conforme apresentado na Figura 1. O lixo é definido de imediato como algo sem utilidade, por isso seu descarte é feito, por grande parte da população, sem se pensar na possibilidade de fazer a reciclagem ou reutilização de alguns produtos, consequentemente, a produção de lixo se intensifica cada vez mais, se tornando um dos maiores problemas socioambientais, pela falta de conhecimento sobre o descarte e tratamento adequado que poderiam assim amenizar a produção desses resíduos.

A educação ambiental vem como principal proposta de intervenção para este problema, objetivando "proporcionar aprendizado e promover mudança de atitudes dos estudantes em prol do desenvolvimento sustentável" (Souza, 2020). Mudança essa que reduziria a produção de lixo, por meio de reciclagem e reaproveitamento do máximo de materiais possíveis, minimizando assim desperdícios e auxiliando até mesmo na estabilidade climática, visto que a reciclagem diminui de maneira significativa o processo de produção de gases do efeito estufa.

Figura 1 - Percentual de entrevistados, no ano 2021, em relação a (A) preocupação com as questões ambientais e (B) opinião sobre consciência ambiental.
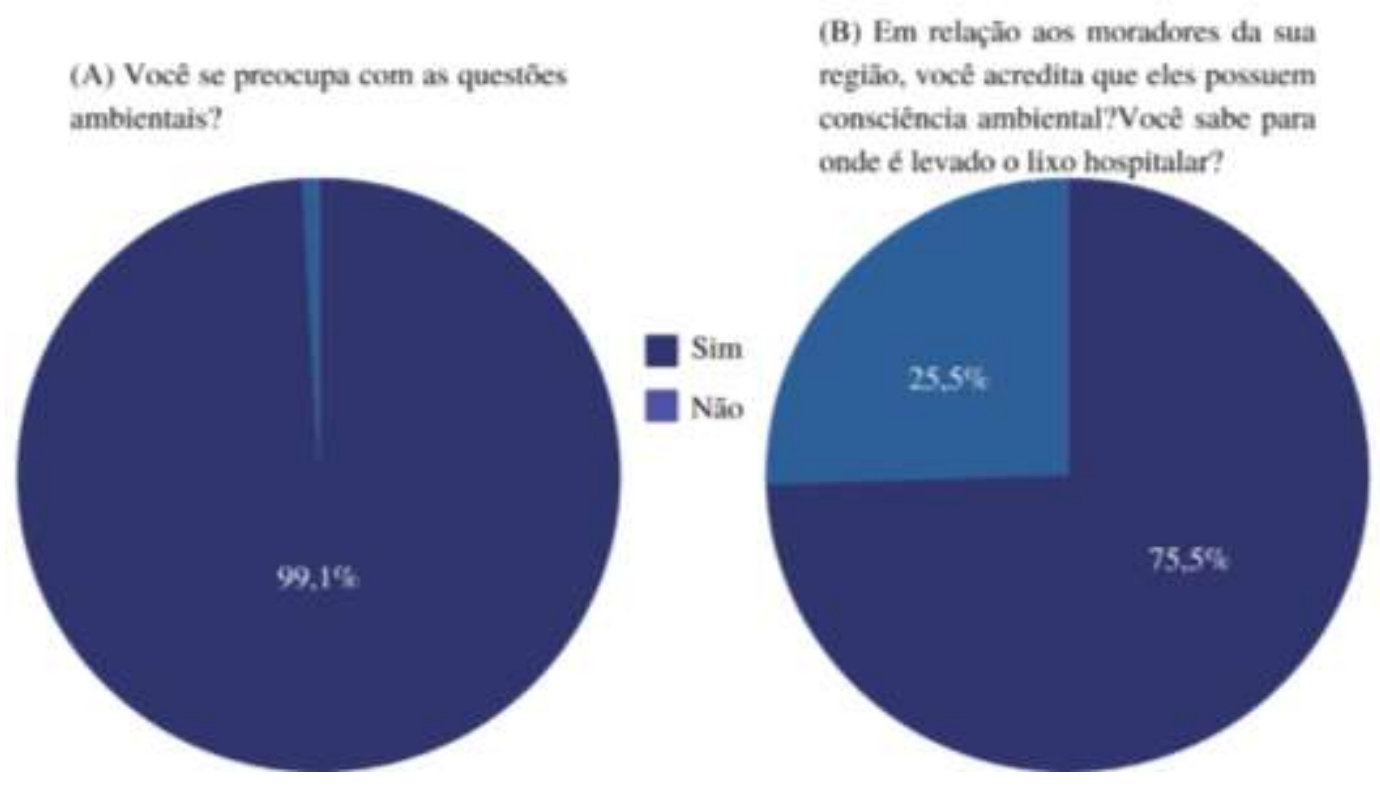

Fonte: Autores (2021).

Os entrevistados foram questionados se quando vão as compras, se preocupam em escolher produtos que agridam menos o meio ambiente. Nesse caso, 45,52\% disseram que sim, e 54,48\% não. Além disso, os entrevistados responderam se nas ruas de seu bairro há lixeiras para jogar o lixo, e os dados mostraram que 41,61\% das ruas sim e 58,39\% não. Quando questionados se costumam utilizar as lixeiras disponíveis nas ruas, 88,70\% afirmaram que sim e 11,0\% respondera não (Figura 2). É possível perceber que uma maioria dos entrevistados não tem a devida preocupação em escolher produtos que sejam reutilizáveis e/ou biodegradáveis, úteis para a diminuição de agressão ambiental e facilitar para a coleta seletiva (Figura 2A).

Já a Figura 2 (B e C) demonstra contraste entre as respostas, afirmando que se houvesse-uma maior quantidade de lixeiras disponíveis nos bairros a utilização dela seria de grande uso para a maioria. Filho et al. (2017) destacaram a importância da distribuição de lixeiras e sacolas biodegradáveis, as quais se mostraram eficazes como alternativa de incentivo 
à separação dos materiais, amenizando o impacto dos resíduos vindos de descartes inadequados, além de sensibilizar a população quanto ao descarte correto do lixo.

Figura 2 - Percentual da pesquisa, ano 2021, referentes às perguntas (A) Quando você vai às compras, se preocupa em escolher produtos que agridam menos o meio ambiente? (B) Nas ruas de seu bairro, há lixeiras para jogar o lixo? (C) Você costuma utilizar as lixeiras disponíveis nas ruas?

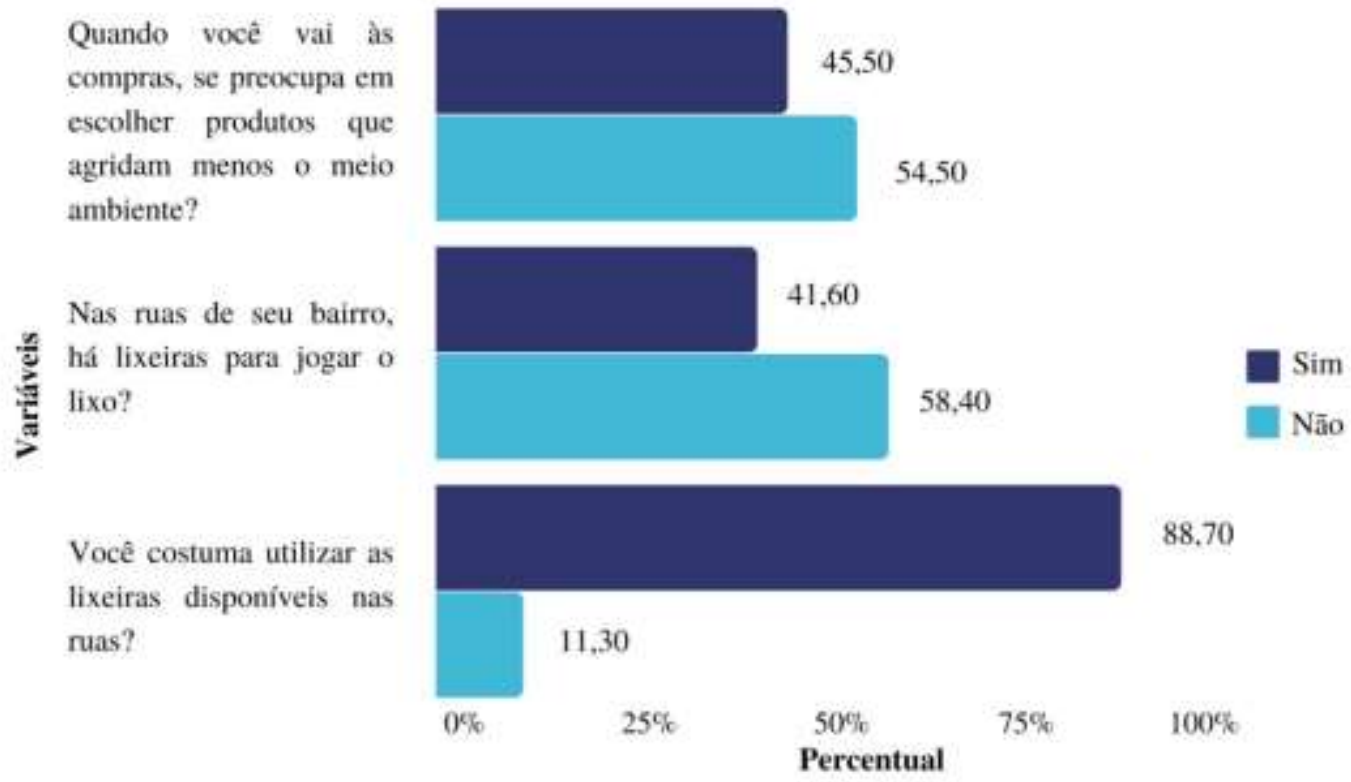

Fonte: Autores (2021).

Segundo a análise abordada na Figura 3, o gráfico (A), sobre o conhecimento do destino do lixo gerado, um total de $60,9 \%$ dos questionados relatou sim, mas 39,1\% afirmaram que não sabem. Sobre o descarte de lixo hospitalar, a Figura 3 , gráfico (B), mostra que são poucos os que sabem para onde é feita a destinação final, chegando apenas a 18,2\% do total de entrevistados.

Figura 3 - Percentual da pesquisa feita no estado do Pará, em 2021, relacionada ao conhecimento da população referente ao destino do lixo doméstico e hospitalar.

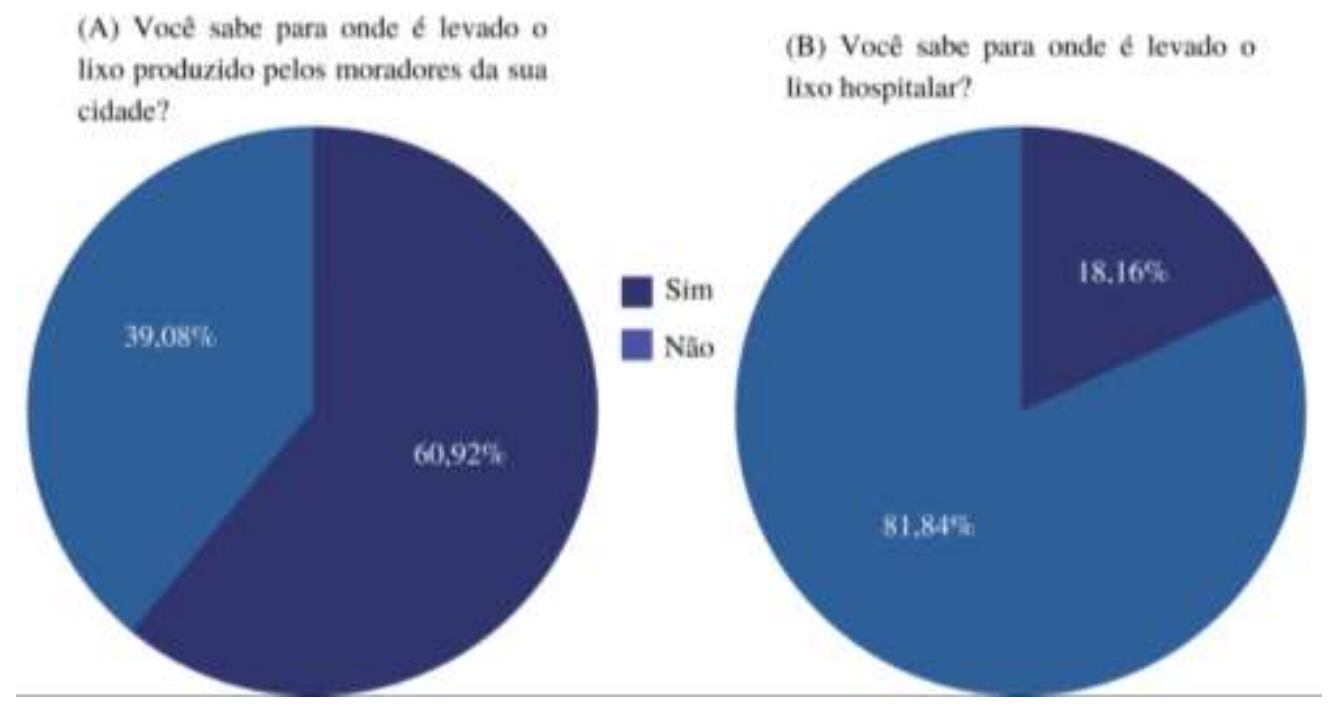

Fonte: Autores (2021). 
Com o crescente aumento na população, a produção de lixo torna-se cada vez maior. Devido a esse fato, o planejamento cabível com aterros controlados e sanitários não é o bastante para a destinação final de resíduo sólido, fazendo com que haja presença de lixões, e com isso a população torna-se vulnerável diante das contaminações que o lixo pode causar a saúde, bem como ao meio ambiente. Conforme Tadeu, Lima e Pozo (2018), cerca de 10\% dos resíduos urbanos são descartados de forma inadequada, enterrados no quintal, queimados em terrenos baldios e/ou encaminhados para outras destinações.

É válido entender que as soluções para a melhora no descarte do lixo passam pelo investimento em educação e ensinamentos dos benefícios da coleta de lixo e da reciclagem, por quais maneiras podem ser realizadas esses processos, e como podem trazer benefícios para a sociedade e o meio ambiente (Silva, 2015). Com a devida sensibilização da comunidade sobre assuntos que permeiam a saúde e o ambiente, será possível diminuir o acúmulo de lixo, permitindo assim uma melhoria na qualidade de vida.

Na Figura 4, os entrevistados foram questionados quanto a conscientização da coleta seletiva de lixo, onde 88,28\% estão cientes do que se trata, e 11,72\% não sabem o que significa; logo após responderam sobre a destinação adequada para o lixo nos municípios, $42,30 \%$ disseram sim e $57,70 \%$ que não. Posteriormente foram abordados quanto à reutilização de alguns materiais que acabariam indo para o lixo, e 62,07\% afirmaram que faziam uso desses materiais, e 37,93\% não.

De acordo com o coordenador da Coleta Seletiva do Lixo da Secretaria Municipal de Saneamento (Sesan), o desafio para efetivar ainda mais esse trabalho depende da própria população em relação a essa coleta seletiva, sendo um dos maiores entraves. O resíduo domiciliar é uma responsabilidade compartilhada, porém, ainda apresenta resistência quanto ao processo de separação, o que para muitos é lixo, para as cooperativas é fonte de renda (Dias, 2020).

Figura 4 - Percentual da pesquisa, ano 2021, referentes às perguntas (A) Você sabe o que é coleta seletiva? (B) Na sua cidade, existe algum ponto específico para a coleta seletiva de lixo? (C) Você costuma reutilizar algum material que vai para o lixo?

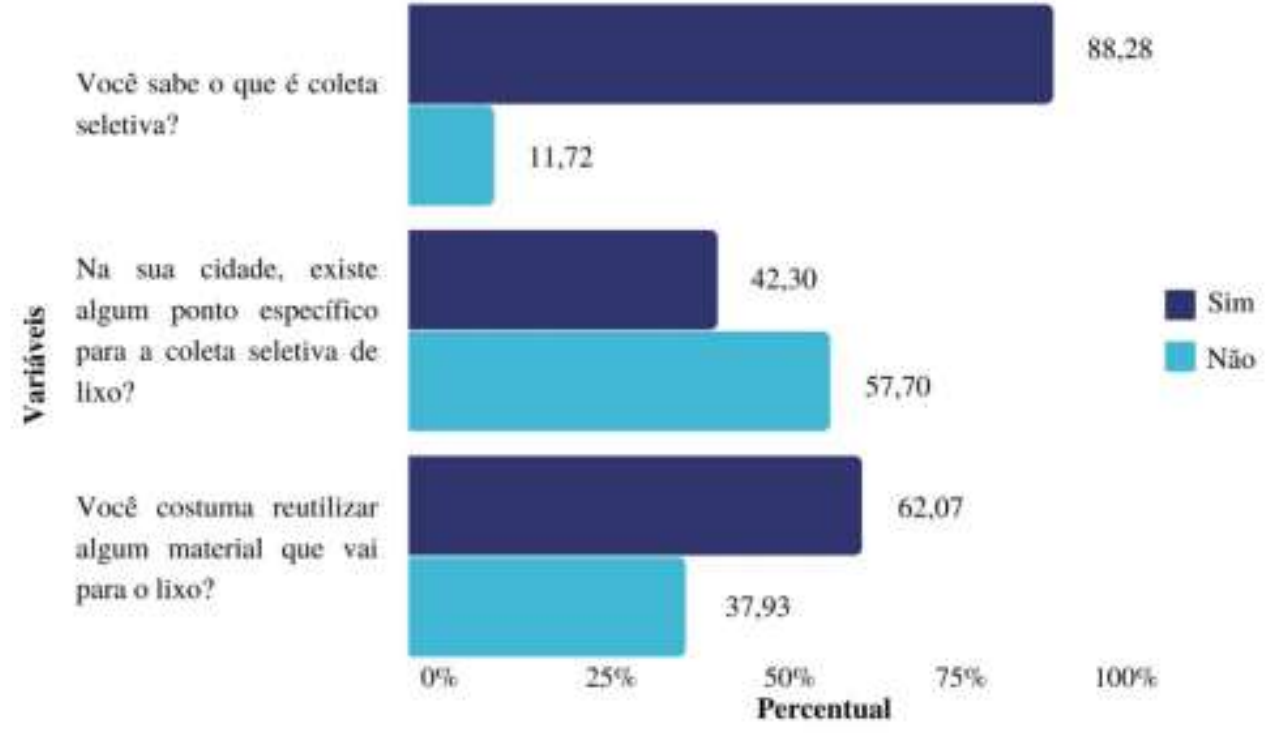

Fonte: Autores (2021).

A pesquisa aponta na Tabela 2, que 85,99\% dos entrevistados separam o lixo para ser coletado pelo caminhão da prefeitura, 10,99\% separam para reciclagem, 2,37\% queimam e 0,65\% jogam em terrenos baldios, tendo casos em que alguns entrevistados, além de separar para a coleta fazem reciclagem, através de artesanatos e/ou adubos orgânicos. 
Tabela 2 - Percentual do destino do lixo domiciliar no estado do Pará, ano 2021.

\begin{tabular}{lc}
\hline Destino & $\%$ \\
\hline Separa para ser coletado pelo caminhão da prefeitura & 85,99 \\
Reciclagem & 10,99 \\
Queima & 2,37 \\
Joga em terrenos baldios & 0,65 \\
\hline Total & 100,00 \\
\hline
\end{tabular}

Fonte: Autores (2021).

Segundo a Revista Galileu (2020), em 2018, o Brasil gerou 79 milhões de toneladas de resíduos por ano, um aumento de quase $1 \%$ em relação ao ano anterior, de acordo com o panorama de resíduos sólidos de 2018 elaborado pela Associação Brasileira de Empresas de Limpezas Públicas e Resíduos especiais (ABRELPE). Desse total, estima-se que apenas 3\% seja efetivamente reciclado e potencialmente $30 \%$. “[...] a visão de que simplesmente ter um aterro e um sistema de coleta resolvia o problema não mudou. Não é o caso”, disse Ana Maria Luz, presidente do GEA - Instituto de Ética e Meio Ambiente.

Foi notado que a maioria dos entrevistados estão inclusos entre naqueles que só separam para a coleta e não reutilizam os materiais recicláveis para fazer artesanato. Outros dados importantes elaborados na pesquisa estão relacionados ao descarte do lixo da população da área rural onde na tabela acima é apresentado que 0,65\% de diversas cidades jogam em terrenos baldios e 2,37\% dos questionados queimam, prejudicando assim o meio ambiente pela falta de assistência adequada para a coleta.

\section{Conclusão}

Diante a pesquisa apresentada, ficou evidente o quanto a população tem um papel decisivo perante os resíduos sólidos que produzem, desde o manejo até o descarte final. As cidades alcançadas ainda têm muito que avançar no que diz respeito a esforços para melhoria na gestão de resíduos sólidos, pois a redução dos impactos ambientais só terá sucesso quando houver mobilização e apoio por parte dos governos e prefeituras. De modo geral, é preciso investir na educação ambiental da população, para que as futuras gerações possam contribuir positivamente para o bom desenvolvimento socioambiental. A conscientização tratada neste trabalho deverá acontecer particularmente, por se tratar de hábitos diários e estilo de vida e consumo, mas o trabalho em si, depende de um esforço contínuo e conjunto de todos. Na maioria dos casos, pode ser observado que há o conhecimento sobre o assunto abordado, mas falta ainda a conscientização partindo de cada um para a verdadeira mudança. Porém, é importante ressaltar que por mais que haja uma mobilização de governos e prefeituras, nada adianta se a população não medir esforços quanto ao consumo insustentável, desperdício e a necessidade na diminuição de lixo gerado. Toda ação de reciclagem e coleta seletiva será ilusória, caso a população não esteja consciente de seu papel, de estarem consumindo ainda mais produtos por serem recicláveis e considerados ecológicos, e no fim, não terão o devido retorno de que a reciclagem será suficiente para tornar o consumo sustentável.

Para desenvolvimento futuro, surgiram alguns aspectos relevantes que podem ser utilizados numa abordagem de estudos: Compreender melhor o processo de reutilização de materiais recicláveis que os entrevistados usam, e tomar como base para a diminuição da produção de resíduos sólidos e assim gerar renda para as pessoas. Além de pesquisar mais a fundo sobre qual o destino e o que é feito com o resíduo hospitalar gerado nas cidades, e como a falta de conhecimento sobre o descarte incorreto pode gerar riscos à saúde e impactos ambientais graves, e sobre quanto as políticas públicas na contratação de cooperativas de catadores, incentivos para coleta seletiva e reutilização de materiais pode gerar benefícios para a sociedade e o meio ambiente. 
Research, Society and Development, v. 10, n. 16, e584101623198, 2021

(CC BY 4.0) | ISSN 2525-3409 | DOI: http://dx.doi.org/10.33448/rsd-v10i16.23198

\section{Referências}

Cornieri, M. G., \& Fracalanza, A. P. (2010). Desafios do lixo em nossa sociedade. Brazilian Journal of Environmental Sciences (Online), (16), 57-64. http://rbciamb.com.br/index.php/Publicacoes_RBCIAMB/article/view/389

Dias, J. T. (2020). Coleta seletiva só é possível com separação do lixo. https://www.oliberal.com/mobiliza/noticia/coleta-seletiva-so-e-possivel-comseparacao-do-lixo-1.248832

Farias, M. F. D. S. (2019). Trabalho de Conclusão de Curso (Graduação) - Curso de Agronomia, Campus Universitário de Belém, Universidade Federal Rural da Amazônia. sustentabilidade e meio ambiente: a percepção dos moradores da região metropolitana de Belém, Pará, Amazônia, Brasil.

G1. (2021). Pará é o estado que menos recicla no Brasil. https://g1.globo.com/pa/para/noticia/2021/06/06/para-e-o-estado-que-menos-recicla-no-brasil.ghtml

Gandra, A. (2020). Quase metade dos municípios ainda despeja resíduos em lixões. https://agenciabrasil.ebc.com.br/geral/noticia/2020-08/quase-metadedos-municipios-ainda-despeja-residuos-em-lixoes

IBGE - Instituto Brasileiro de Geografia e Estatísticas. (2019). IBGE divulga estimativa da população dos municípios para 2020 https://agenciadenoticias.ibge.gov.br/agencia-sala-de-imprensa/2013-agencia-de-noticias/releases/28668-ibge-divulga-estimativa-da-populacao-dosmunicipios-para-2020

IBGE - Instituto Brasileiro de Geografia e Estatísticas. (2021). https://www.ibge.gov.br/cidades-e-estados

Brasil, Lei $\mathrm{n}^{\mathrm{o}} 12.305$ de 02 de agosto de 2010. Política Nacional de Resíduos Sólidos (PNRS). http://www.planalto.gov.br/ccivil_03/_ato20072010/2010/lei/112305.htm

Mucelin, C. A., \& Bellini, M. (2008). Lixo e impactos ambientais perceptíveis no ecossistema urbano. Sociedade \& natureza,20, 111-124. DOI: $10.1590 /$ S1982-45132008000100008

Pereira, A. S., Shitsuka, D. M., Parreira, F. J., \& Shitsuka, R. (2018). Metodologia da pesquisa científica.[e-book]. Santa Maria: UAB/NTE/UFSM, https://repositorio.ufsm.br/bitstream/handle/1/15824/Lic_Computacao_Metodologia-Pesquisa-Cientifica.pdf?sequence=1 .

Schott Filho, O., Aguiar, A. C. D. M., Silva, E. D. C. R. D., Pereira, T. C., Ferreira, J. A., \& Borges, A. C. (2017). Projeto Estiva: uma iniciativa de gestão de resíduos sólidos urbanos em comunidades de baixa renda. DOI: https://doi.org/10.21284/elo.v6i3.273

Silva Souza, F. R. (2020). Educação Ambiental e sustentabilidade: uma intervenção emergente na escola. Revista Brasileira de Educação Ambiental (RevBEA), 15(3), 115-121. DOI:https://doi.org/10.34024/revbea.2020.v15.9616

Silva, N. M. D., \& Nolêto, T. M. S. D. J. (2004). Reflexão sobre lixo, cidadania e consciência ecológica. Geoambiente On-line-Revista Eletrônica do Curso de Geografia do Campus Avançado de Jataí, (2). DOI: https://doi.org/10.5216/rev.\%20geoambie.v0i2.25863

Souza Silva, A. R., de Melo, D. G., da Silva Moraes, F. J., Antônio, T., Coelho, T. P. M., \& da Silva, G. S. (2015). Impactos ambientais referentes à não coleta de lixo e reciclagem. Caderno de Graduação-Ciências Exatas e Tecnológicas-UNIT-ALAGOAS,2(3), 63-76. Retirado de https://periodicos.set.edu.br/fitsexatas/article/view/2136

Tadeu, C. E., de Lima, J. G., \& Pozo, O. V. C. (2018). Estudo sobre a percepção do cidadão lavrense em relação ao descarte de lixo. Brazilian Journal of Production Engineering-BJPE, 99-115. DOI: https://doi.org/10.0001/v4n1_7

Vassanadumrongdee, S., \& Kittipongvises, S. (2018). Factors influencing source separation intention and willingness to pay for improving waste management in Bangkok, Thailand. Sustainable Environment Research, 28(2), 90-99. DOI: https://doi.org/10.1016/j.serj.2017.11.003

Vilhena, A. (Coord.). (1999). Guia da coleta seletiva de lixo. São Paulo: CEMPRE - Compromisso Empresarial para Reciclagem. https://cempre.org.br/wpcontent/uploads/2020/11/4-GuiadaColetaSeletiva2014.pdf 